\title{
Can we use Google trends to estimate the demand for plastic surgery?
}

\author{
H. Luze ${ }^{1,2}$ - S. P. Nischwitz ${ }^{1,2}$ • P. Kotzbeck ${ }^{1,2}$ - L. P. Kamolz ${ }^{1,2}$ \\ Received: 13 January 2020 / Accepted: 5 March 2020 / Published online: 11 April 2020 \\ (C) The Author(s) 2020
}

Nowadays, patients interested in aesthetic plastic surgery procedures increasingly seek advice on social media and search engines [1]. Since Google is the most popular search engine worldwide, Google Search is an important tool for patients researching aesthetic plastic surgery procedures and finding hospitals or even single surgeons [2]. Google compiles and provides these search data to the public, through a platform called Google Trends (GT) [3] (Alphabet Inc., Mountain View, California, United States). Research in health care has used GT data to explore public interest and trends, for example, on complementary and alternative medicine, urolithiasis, flu or bariatric surgeries [4-7]. In the field of Plastic, Aesthetic and Reconstructive Surgery, Google trends has for instance been used to detect patients' insights to the latest trends, interest in breast augmentation or cosmetic body procedures in general. [8, 9]

Based on a similar study from the USA by Blau et al., the aim of this study was to investigate the relative popularity of internet searches for plastic and aesthetic surgery across Austria for a 12-month period in order to compare these data to the number of plastic surgeons in each state [10]. In the present study, facts such as median income and bedoccupancy rates of Plastic, Aesthetic and Reconstructive Surgery (PARS) Departments were additionally included, to

H. Luze

hanna.luze@medunigraz.at

1 COREMED - Cooperative Centre for Regenerative Medicine, JOANNEUM RESEARCH Forschungsgesellschaft mbH, Graz, Austria

2 Department of Surgery, Division of Plastic, Aesthetic and Reconstructive Surgery, Medical University of Graz, Graz, Austria identify regional market needs for aesthetic plastic surgery procedures in every state of Austria.

Data was obtained from several sources. Google data is reported as the relative search volume (RSV) for all searches for "Plastic Surgery" and "Aesthetic Surgery" for the year 2017 (12-month period). Data is reported state-by-state, and normalized by the total search volume. The frequency of a search is divided by the total number of searches over the same time and geographic distribution. This adjustment is managed by Google; hence, the state with the highest search volume does not necessarily hold the highest ranking. Data is reported on a scale from 0 to 100 based on a proportion to all searches [3].

Based on data provided by Statistik Austria, the statistics department of Austria, the ratio of plastic surgeons per 10,000 people in each state and the capacity and bed-occupancy rate of PARS Departments were calculated.

Based on a similar study from the USA, the surgical demand index (SDI), which is a measure of how the concentration of plastic surgeons matches the public curiosity with plastic surgery, was used [10]. The index is calculated by dividing the Google relative search volume (RSV) by the concentration of plastic surgeons in any individual state, according to the formula:

Surgical Demand index $=\frac{\text { Google Relative Search voume }}{\text { Plastic Sugeons per } 10000 \text { People }}$

Descriptive statistics were applied on median income, bedoccupancy rate of PARS Departments and number of surgeons per 10,000 people. For calculating correlations between income, surgical concentration, SDI, RSV and bed-occupancy rate, GraphPad Prism 8.1.2 was used. The Pearson correlation coefficient ( $\mathrm{r}$ ), a measure of the linear correlation between two variables $\mathrm{X}$ and $\mathrm{Y}$, was determined. The coefficient has a value 


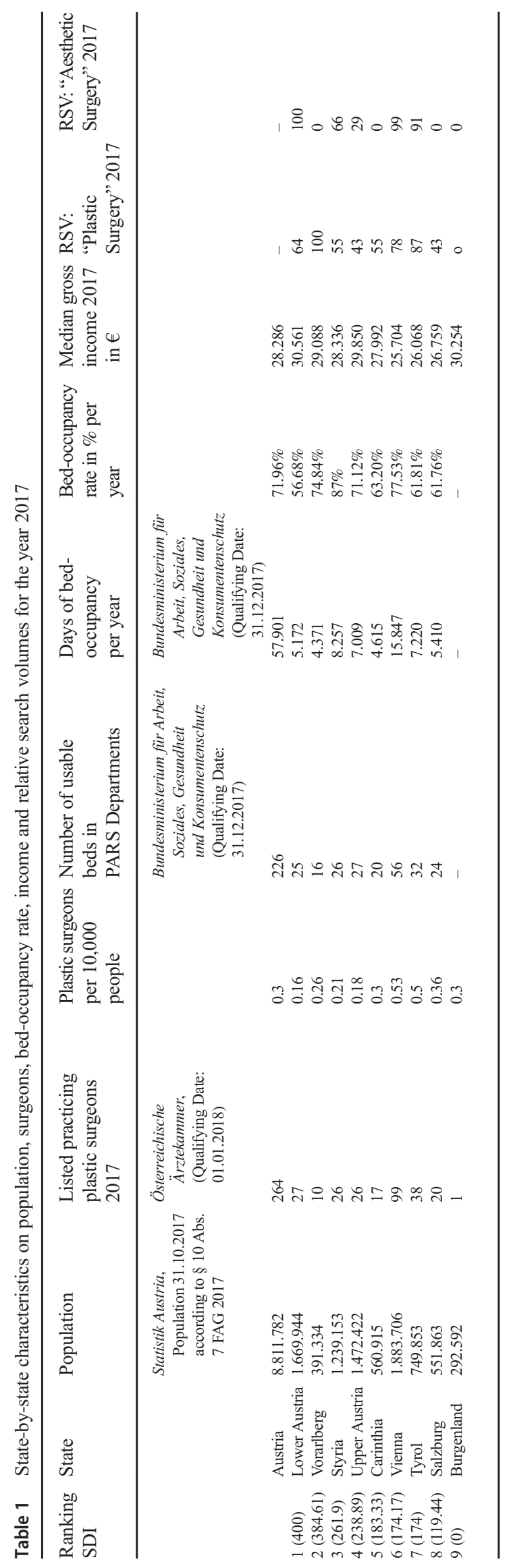

between +1 and -1 , where 1 is the total positive linear correlation, 0 is no linear correlation and -1 is total negative linear correlation.

With a size of nearly $84,000 \mathrm{~km}^{2}$, Austria is divided into 9 states: Lower Austria (LA), Upper Austria (UA), Salzburg (SA), Tyrol (TY), Vorarlberg (VA), Carinthia (CA), Styria (ST), Burgenland (B) and Vienna (V), which is the capital of Austria as well. Relative search volume, concentration of plastic surgeons, surgical demand and bed-occupancy rates were calculated for each state to identify regional market needs. An additional overview of all results is presented in Table 1 .

With regard to the search term "Plastic Surgery" in 2017, Vorarlberg had the highest RSV at 100 (a benchmark used to calibrate all other states), followed by Tyrol (87), Vienna (78), Styria (55) and Carinthia (55). The lowest RSV was reported in Salzburg (43) and Upper Austria (43). Insufficient data was found for Burgenland (0).

The highest RSV for the search term "Aesthetic Surgery" in 2017 was reported in Lower Austria (100) followed by Vienna (99) and Tyrol (91), Styria (66) and Upper Austria (29). Insufficient data was found for Vorarlberg (0), Carinthia (0), Salzburg (0) and Burgenland (0).

In comparison with the USA, where $0.05-0.22$ surgeons per 10,000 people are reported [10], concentration in Austria is mostly significantly higher. Two hundred sixty-four practicing plastic surgeons were registered in Austria in 2017, whereby Vienna had the biggest score (99) and Burgenland the smallest (1). The ratio of surgeons to the state population yielded similar results. Vienna also ranked at the top with 0.53 surgeons per 10,000 people, closely followed by Tyrol with 0.5 .

Salzburg took third place with 0.36 before Carinthia (0.3), Vorarlberg (0.26), Styria (0.21), Upper Austria (0.18) and Lower Austria (0.16). The least-dense state was Burgenland with 0.03 . These data are presented in Fig. 1.

SDI was calculated with the RSV of the search term "Plastic Surgery" in 2017. Demand for plastic surgeons was highest in Lower Austria (400) followed by Vorarlberg (384.61), Styria (261.9) and Upper Austria (238.89), Carinthia (183.33), Vienna (174.17) and Tyrol (174). Demand was lowest in Salzburg (119.44). Not enough data could be extracted for Burgenland (0) (see Fig. 2). Compared to the study by Blau et al., lowest demand in the USA (Oregon, 264.683) [10] was still higher than the average SDI in Austria (242.04). Highest demand in the USA (Wyoming, 1187.778) [10] presented a much higher demand than the highest value in Austria. This does not necessarily mean that patients in the USA are generally more interested in aesthetic, plastic procedures, but demonstrates a weaker supply due to a 
smaller concentration of plastic surgeons in the USA. Due to a high concentration of plastic surgeons in Austria, and therefore a better supply, surgical demand calculated with the SDI presents significantly lower compared to the USA.

Bed-occupancy rates of Plastic, Aesthetic and Reconstructive Surgery Departments per year, based on the number of usable beds in PARS Departments and the days of actual usage per year, the maximum capacity and the actual bed-occupancy rate of each state were calculated for 2017. A capacity of $100 \%$ presents full bedoccupancy during the whole year. For the year 2017, Styria ranks at the top with a bed-occupancy rate of $87 \%$, followed by Vienna (77.53\%), Vorarlberg (74.84\%), Upper Austria (71.12\%) and Carinthia (63.2\%). Lowest bed- occupancy rate is reported in and Tyrol (61.81\%), Salzburg (61.76\%) and Lower Austria (56.68\%). Insufficient data was found for Burgenland (0) (see Fig. 1).

Google relative search volume (Plastic Surgery in 2017) was used to predict surgical concentration. This relationship demonstrated a positive correlation with $r=0.652$. Even though results are not statistically significant $(p=0.0570)$, a trend towards a correlation between surgical concentration and RSV is recognizable.

Median gross income per year was used to predict Google RSV. We differed in the search terms "Plastic Surgery" and "Aesthetic Surgery" (see Fig. 3). This relationship demonstrated slightly negative correlation for both, RSV with the search term "Plastic Surgery" $(r=-0.431)$ and RSV with the search term "Aesthetic Surgery" $(r=-0,276)$. Results
Fig. 1 Concentration of plastic surgeons and bed-occupancy rates of PARS Departments in each state

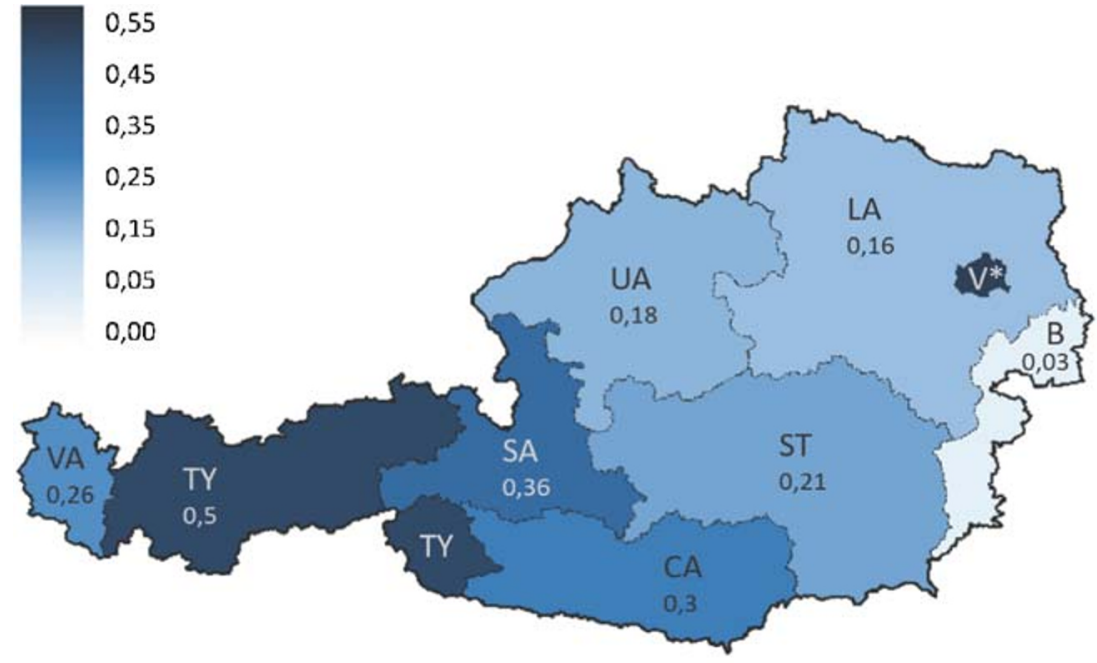

Concentration of Plastic surgeons (Surgeons per 10000 people), *Vienna: 0,53

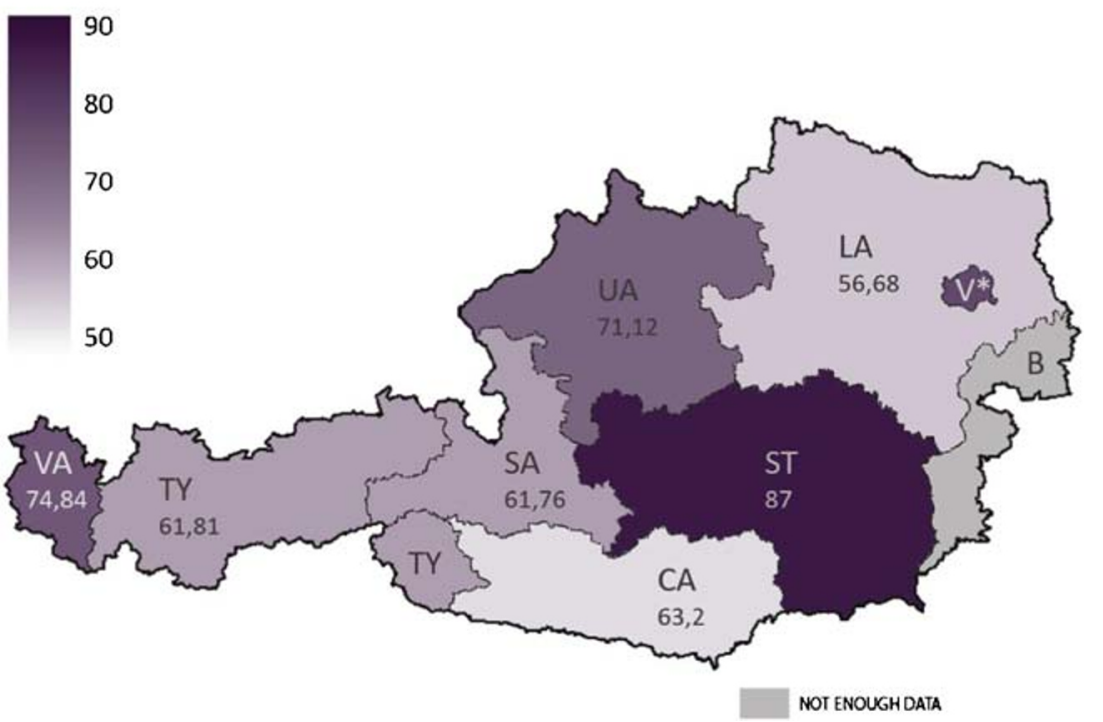

Bed-occupancy rate of PARS Departments in each state per year. *: Vienna: $77,53 \%$ 
Fig. 2 Surgical demand index for each state

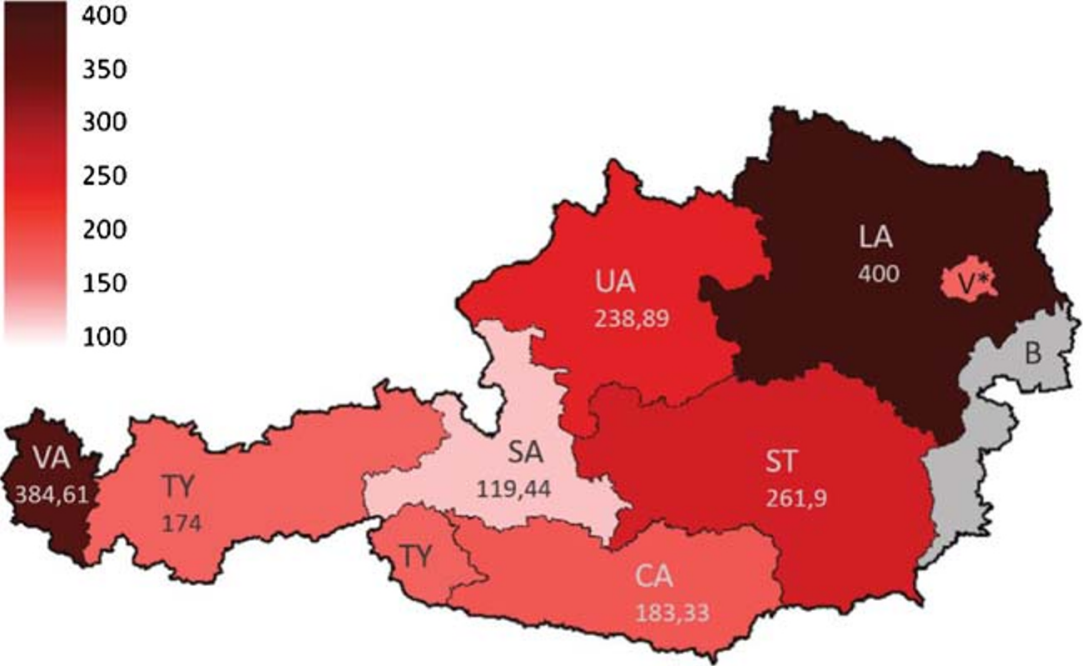

NOT ENOUGH DATA

Surgical Demand Index for each state, *Vienna: 174,17

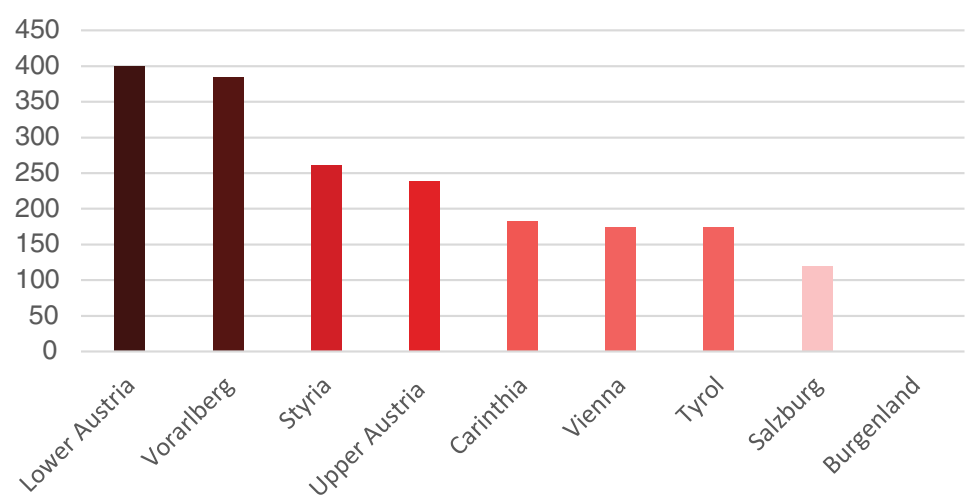

are neither statistically significant for "Plastic Surgery" ( $p=$ 0.2470 ) nor for "Aesthetic Surgery" ( $p=0.4723)$. We first suggested that higher median gross income would correlate with higher RSV for Plastic and especially Aesthetic Surgery, but interestingly, results showed that correlation is rather slightly negative. As well, no correlation between high RSV and income-richer patients was found by Blau et al. in the USA [10]. Generally spoken, income-richer patients are not

Fig. 3 Median gross income per year vs. RSV "Plastic Surgery" vs. RSV "Aesthetic Surgery"
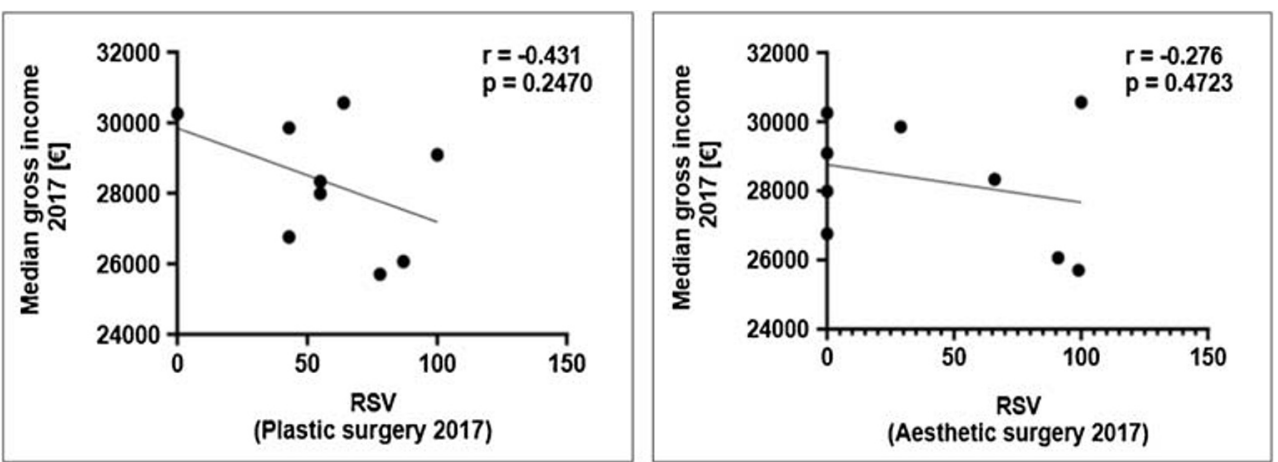
searching for plastic or aesthetic surgery more frequently, at least not via Google.

Since patients are increasingly searching for information on plastic surgery on the Internet, a lot of data can be extracted from search histories. The freely accessible, massive Google data set has already been used in many topics, but is yet quite new in Plastic, Aesthetic and Reconstructive Surgery.

This study showed that distribution of interest in plastic surgery and distribution of plastic surgeons is not homogeneous. On the one hand, there are states with excessive interest in plastic surgery, while the concentration of surgeons is midrange (e.g. Vorarlberg). On the other hand, there are states with lower interest that rank top in concentration of surgeons (e.g. Vienna, Tyrol). Differences in surgical density could not clearly be explained by income disparities or differences in public interest in plastic surgery, although a positive trend in the correlation of surgical concentration and RSV was reported.

In the present study, capacities and bed-occupancy rates of PARS departments were additionally analysed and frequently low bed-occupancy detected (e.g. Lower Austria, Salzburg, Tyrol). In this context, university hospitals in Graz (Styria), Vienna and Innsbruck (Tyrol) are particularly important due to their supra-regional supply responsibilities. They present major supply centres for advanced medicine where high capacity and an effective care system is necessary. To ensure adequate capacity for hospitalizing problematic cases from other states, the increase of resources may be required, where high bed-occupancy rates are found. On the other hand, low bed-occupancy rates may be caused by a lack of isolation rooms for patients with problematic germs, where other rooms must be blocked. In this case, additional isolation rooms should be considered to not waste other resources.

Where high SDI and low bed-occupancy is reported (e.g. Lower Austria), people are possibly more interested in aesthetic procedures. Departments in the concerned states should reconsider the need of restructuring capacities to outpatients' clinic for a more efficient use of resources. Nevertheless, results showed that PARS Departments are well distributed throughout Austria. Compared to the USA, average SDI in Austria (242.04) is still lower than the lowest demand in the USA (Oregon, 264.683) [10]. In contrast to the USA, no additional institutions but rather reallocation of resources is necessary in Austria.

These data offer several possible applications, but may mainly be relevant for PARS Departments to optimize capacity and surgeons who strive to work in a private practice to recognize undersupplied areas, while the market in other states is saturated. Relevance of statistics like these is certain and may be useful as an additional information source for a better supply of the constantly changing demand. However, they are inadequate for planning when used as the sole source.

Funding Information Open access funding provided by Medical University of Graz.

\section{Compliance with ethical standards}

Conflict of interest H. Luze, S. P. Nischwitz, P. Kotzbeck and L. P. Kamolz declare that they have no conflict of interest.

\section{Funding statement None}

Ethical approval For this type of study, formal consent is not required.

Open Access This article is licensed under a Creative Commons Attribution 4.0 International License, which permits use, sharing, adaptation, distribution and reproduction in any medium or format, as long as you give appropriate credit to the original author(s) and the source, provide a link to the Creative Commons licence, and indicate if changes were made. The images or other third party material in this article are included in the article's Creative Commons licence, unless indicated otherwise in a credit line to the material. If material is not included in the article's Creative Commons licence and your intended use is not permitted by statutory regulation or exceeds the permitted use, you will need to obtain permission directly from the copyright holder. To view a copy of this licence, visit http://creativecommons.org/licenses/by/4.0/.

\section{References}

1. Montemurro P, Porcnik A, Hedén P, Otte M (2015) The influence of social media and easily accessible online information on the aesthetic plastic surgery practice: literature review and our own experience. Aesthet Plast Surg 39(2):270-277

2. Ratcliff C (2016) What are the top 10 most popular search engines?. [Online]. Available: https://searchenginewatch.com/2016/08/08/ what-are-the-top-10-most-popular-search-engines/

3. "Google Trends." [Online]. Available: https://trends.google.com/ trends/?geo=US

4. Zevallos-Morales A, Málaga M, Taype-Rondan A Trends in Google searches on complementary and alternative medicine. Rev Med Inst Mex Seguro Soc 55(2):161-169

5. Raheem OA, Khandwala YS, Sur RL, Ghani KR, Denstedt JD (Feb. 2017) Burden of urolithiasis: trends in prevalence, treatments, and costs. Eur Urol Focus 3(1):18-26

6. Pollett $\mathrm{S}$ et al (2017) Evaluating Google flu trends in Latin America: important lessons for the next phase of digital disease detection. Clin Infect Dis 64(1):34-41

7. Rahiri J-L, Barazanchi A, Furukawa S, MacCormick AD, Harwood M, Hill AG (2018) Using Google trends to explore the New Zealand public's interest in bariatric surgery. ANZ J Surg 88(12): 1274-1278 
8. Wilson SC, Daar DA, Sinno S, Levine SM (2018) Public interest in breast augmentation: analysis and implications of Google trends data. Aesthet Plast Surg 42(3):648-655

9. Tijerina JD, Morrison SD, Nolan IT, Vail DG, Lee GK, Nazerali R (2019) Analysis and interpretation of Google trends data on public interest in cosmetic body procedures. Aesthetic Surg J
10. Blau JA, Aibel KR, Levites HA, Phillips BT, Hollenbeck ST (2016) Abstract. Plast Reconstr Surg Glob Open 4:39

Publisher's note Springer Nature remains neutral with regard to jurisdictional claims in published maps and institutional affiliations. 